\title{
The role of the mitochondria and the endoplasmic reticulum contact sites in the development of the immune responses
}

\author{
Denis Martinvalet ${ }^{1}$
}

\begin{abstract}
Mitochondria and endoplasmic reticulum (ER) contact sites (MERCs) are dynamic modules enriched in subset of lipids and specialized proteins that determine their structure and functions. The MERCs regulate lipid transfer, autophagosome formation, mitochondrial fission, $\mathrm{Ca}^{2+}$ homeostasis and apoptosis. Since these functions are essential for cell biology, it is therefore not surprising that MERCs also play a critical role in organ physiology among which the immune system stands by its critical host defense function. This defense system must discriminate and tolerate host cells and beneficial commensal microorganisms while eliminating pathogenic ones in order to preserve normal homeostasis. To meet this goal, the immune system has two lines of defense. First, the fast acting but unspecific innate immune system relies on anatomical physical barriers and subsets of hematopoietically derived cells expressing germline-encoded receptors called pattern recognition receptors (PRR) recognizing conserved motifs on the pathogens. Second, the slower but very specific adaptive immune response is added to complement innate immunity. Adaptive immunity relies on another set of specialized cells, the lymphocytes, harboring receptors requiring somatic recombination to be expressed. Both innate and adaptive immune cells must be activated to phagocytose and process pathogens, migrate, proliferate, release soluble factors and destroy infected cells. Some of these functions are strongly dependent on lipid transfer, autophagosome formation, mitochondrial fission, and $\mathrm{Ca}^{2+}$ flux; this indicates that MERCs could regulate immunity.
\end{abstract}

\section{Facts}

1. MERCs are dynamic functional modules enriched in a subset of lipids and specialized proteins that dictate both their structures and functions.

2. The activation of NLRP3 inflammasome and of MAVS-dependent antiviral response takes place at the MERCs, suggesting that these contact sites play a critical role in innate immunity.

3. MERCs play an important role in cellular $\mathrm{Ca}^{2+}$ homeostasis by regulating ER to mitochondrial $\mathrm{Ca}^{2+}$ shuttling. Since $\mathrm{Ca}^{2+}$ signaling is essential for

\footnotetext{
Correspondence: Denis Martinvalet (denis.martinvalet@unige.ch)

'Department of Cell Physiology and Metabolism, Geneva Medical School, 1211 Geneva, Switzerland

Edited by P. Pinton
}

lymphocyte activation, this suggests that MERCs may regulate the activation of these cells during adaptive immunity.

4. MERCs regulate both autophagy and mitochondrial fission; both processes are directly linked to antigen presentation and leukocyte migration, respectively.

5. MERCs are altered in glioma stemlike cells and consequently affect glioma stemlike cell surface glycan expression, as well as susceptibility to cytotoxic lymphocytes.

\section{Open questions}

1. What is the dynamic of the MERCs in immune cells?

2. What are the specific characteristics of immune cell MERCs? 
3. Can MERCs be targeted for immune modulation?

4. MERCs are altered in glioma stemlike cells; is this a new feature of cancer stem cells?

\section{Introduction}

The endoplasmic reticulum (ER), the largest organelle in the cell, is essential for protein synthesis, folding, maturation, transport, lipid synthesis and calcium $\left(\mathrm{Ca}^{2+}\right)$ homeostasis. The dysregulation of the ER protein folding function triggers ER stress leading to apoptosis if not resolved $^{1-4}$. This tentacular ER interacts with other organelles to form membrane contact sites. At the mitochondria and ER membrane contact sites (MERCs) the two organelles are $\sim 15-50 \mathrm{~nm}$ apart ${ }^{3,5-13}$. The portion of membranes involved in these interactions defines the mitochondrial associated membranes (MAMs), which account for $5-20 \%$ of the mitochondrial network ${ }^{3,13,14}$. MERCs are enriched in a subset of lipids and specialized proteins that dictate both their structures and functions ${ }^{3,4,12,15}$. Moreover, the MERCs density, length and thickness depend on the cellular metabolic state and stress level, indicating that MERCs are dynamic and regulated functional units, 13,16,17. Interestingly, the MERCs are crucial for lipid transfer, initiation of autophagosome formation, determination of the mitochondrial fission site, ER-mitochondria $\mathrm{Ca}^{2+}$ shuttling and apoptosis $^{11,14,18-28}$. It appears that MERCs regulate essential functions of cells biology and therefore organ physiology, among which the immune system stands by its crucial defense function.

The immune system, through its fundamental ability to distinguish self (including beneficial commensal microbiota) from non-self is able to robustly eliminate pathogenic entities and toxic molecules while preserving the integrity of the surrounding host tissues ${ }^{29-33}$. To achieve its protective function, the immune system relies on anatomical physical barriers (the skin and the mucosa lining the respiratory, gastrointestinal and urogenital tracts) and a subset of hematopoietically derived cells, called leukocytes (macrophages, dendritic cells, mast cells, neutrophils, eosinophils, and natural killer (NK) cells) ${ }^{29,30}$. Soluble factors, such as the complement system, pentraxins, collectins and the defensins antimicrobial peptides complete this arsenal ${ }^{29,30}$.

These leukocytes express a limited repertoire of germline-encoded receptors called pattern recognition receptors (PRR) recognizing conserved molecular motifs on the pathogens called pathogen associated molecular patterns (PAMPs) ${ }^{29,30,34,35}$. Moreover, the PRR can also sense the damage-associated molecular pattern (DAMPs) released by host cells experiencing trauma related or not to infection ${ }^{30,35}$. Altogether, these first defense lines constitute the innate immune system which is by nature fast acting but not specific ${ }^{29,30,35}$. The detection of PAMPs activates tissue-resident macrophages leading to the production and secretion of the pro-inflammatory cytokine interleukin 1 (IL1) through the formation and activation of the inflammasome, a large protein complex, at the interface of the mitochondria and the ER. This indicates that MERCs play a role in the development of the innate immune response ${ }^{36-40}$. Together, this leads to a state of inflammation in order to alert and to combat the ongoing infection.

Importantly, the innate immune system delivers the antigenic information to activate the adaptive immune system synergizing with the innate response. This adaptive response relies on the $\mathrm{T}$ lymphocytes (effectors of the cellular adaptive response) and the B lymphocytes (the antibody producing cells) harboring receptors encoded by genes requiring somatic rearrangements to be expres$\operatorname{sed}^{31,41,42}$. Consequently, the adaptive response takes time to build-up and comes chronologically after the innate response $^{29,31}$. Interestingly, the lymphocytes activation initiates a phosphorylation cascade resulting, among other things, in the mobilization of the intracellular $\mathrm{Ca}^{2+}$ pool essential for gene expression ${ }^{43-47}$. The ignition and development of both an innate and an adaptive immune response require immune cell activation, phagocytosis and processing of pathogens, migration, proliferation, release of soluble factors, and finally, the destruction of the infected cells. Some of these functions are strongly dependent on lipid transfer, autophagosome formation, mitochondrial fission and $\mathrm{Ca}^{2+}$ flux indicating that MERCs could regulate immunity.

Recent excellent reviews have discussed in great detail the MERCs molecular players and functional implications for $\mathrm{Ca}^{2+}$ and lipid transfer, as well as the mitochondrial metabolism; therefore, this subject will not be addressed here $^{4,6,15,27}$. Instead, in this review, it will be put into perspective how the different function of the MERCs could impact on critical steps of both innate and adaptive immunity and see whether future work could also focus on the MERCs to regulate the host immune system.

\section{MERCs in innate immunity}

The immune system is essential for human survival as in its absence even a minor infection can be lethal ${ }^{48-50}$. Once the physical barrier is breached, microbes access the host organism initiating the activation of innate immunity. Thanks to their toll-like receptors (TLR), a subfamily of PRR, patrolling macrophages are quickly alerted to the invasion $^{32,51-54}$, which initiates the innate immune response and brings a state of inflammation ${ }^{55}$.

This inflammation is triggered by the engagement and the activation of NLRP3 which belongs to the nucleotidebinding oligomerization domain-like receptors (NLRs) ${ }^{56}$, a subfamily of cytosolic PRRs, particularly potent at inducing inflammation following a wide range of stimuli, 


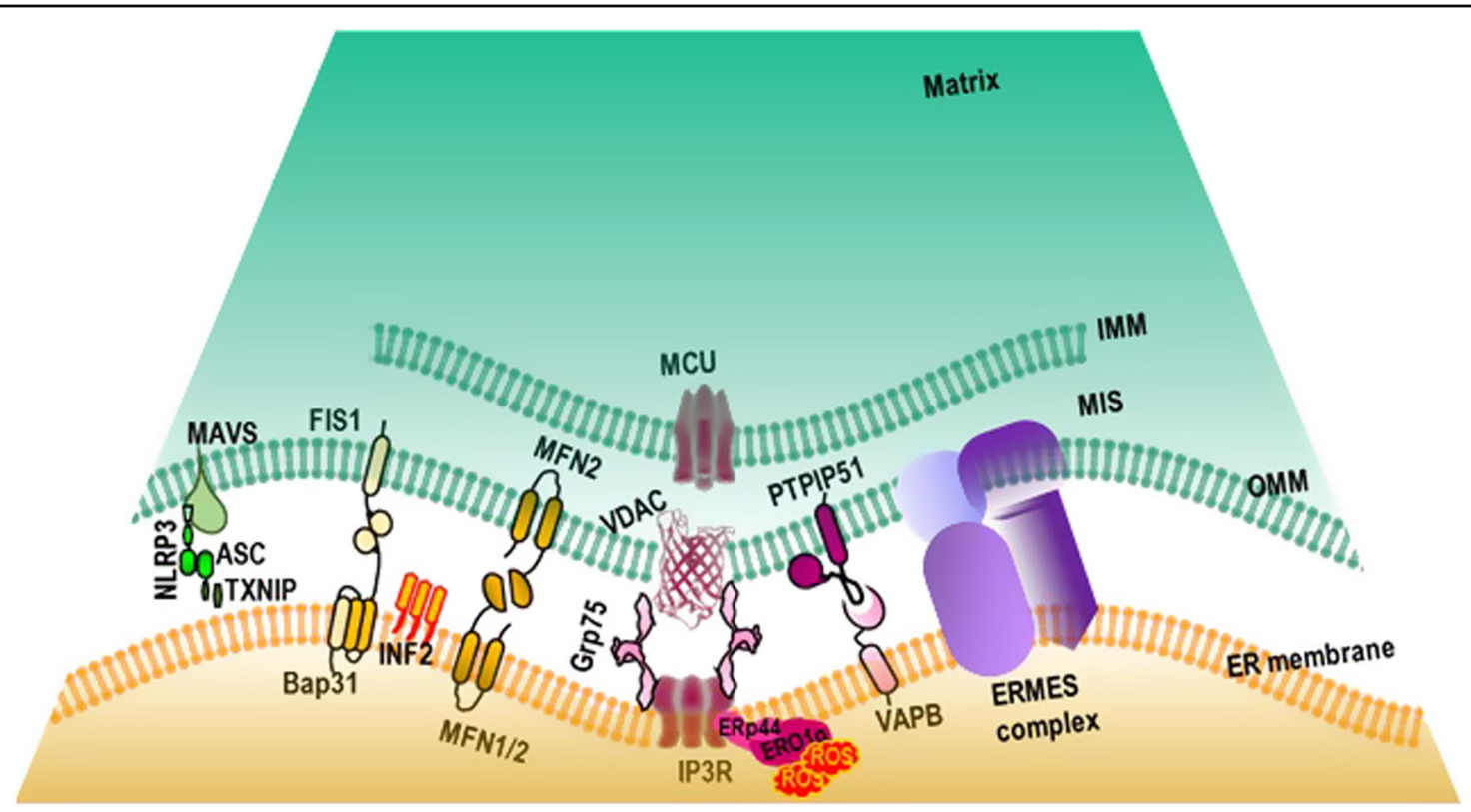

Fig. 1 Graphic representation of the mitochondria-ER contact sites (MERCs) highlighting the principal molecular tethers. Mitochondrion (green) is juxtaposed with the endoplasmic reticulum (ER) (orange) forming an area of contact stabilized by molecular tethers, the nature of which determine the MERCs function. Matrix, mitochondrial matrix; IMM, inner mitochondrial membrane; MIS, mitochondrial intermembrane space; OMM, outer mitochondrial membrane; MCU, mitochondrial calcium uniporter; VDAC, voltage-dependent anion channel; Grp75, 75 kDa glucose-regulated protein; IP3R, inositol 1,4,5 three phosphate receptor; VAPB, vesicle-associated membrane protein-associated protein B; PTPIP51, protein tyrosine phosphatase-interacting protein 51; ERMES, ER-mitochondria encounter structure complex; MFN1 and 2, mitofusin 1 and 2; INF2, inverted formin 2; FIS1, Mitochondrial fission 1; Bap31, B-cell receptor-associated protein 31; MAVS, Mitochondrial antiviral-signaling protein; NLRP3, NOD-like receptors P3; TXNIP, thioredoxin-interacting protein; ASC, apoptosis-associated speck-like protein containing a CARD; ERp44, Endoplasmic reticulum resident protein and ERO1a, oxidoreductin $1 \mathrm{a}$.

such as $\mathrm{ATP}^{57}$, hyaluronan ${ }^{58}$, uric acid crystal and amyloid- $\beta^{59}$. One common feature of these triggers is their ability to induce reactive oxygen species (ROS) production, suggesting that ROS are critical for NLRP3 activation $^{56,60,61}$. The NLRP3 activation and oligomerization recruit the adaptor protein apoptosis-associated specklike protein containing a CARD (ASC) and procaspase 1 to form the high-molecular weight inflammasome protein complex $^{56-61}$. The inflammasome is in fact a platform for caspase 1 activation and caspase 1-mediated processing of pro-IL1 $\beta$ and IL1 $8^{56,57}$. The implication of ROS in NLRP3 activation suggests the involvement of MERCs in inflammation ${ }^{40}$. In unstimulated cells, NLRP3 is associated with the ER, while upon activation, it redistributes to the perinuclear region at the contact site between mitochondria and the ER (Fig. 1) ${ }^{40}$. Moreover, oxidation of active site cysteine thiols of thioredoxin (Trx) leads to the dissociation of thioredoxin-interacting protein (TXNIP) from $\operatorname{Trx}^{39}$ which binds to NLRP3 and robustly activates the inflammasome ${ }^{39}$. Interestingly, both ASC and TXNIP accumulate at the MERCs upon ROSdependent activation (Fig. 1) ${ }^{36-38,40}$. In fact, TXNIP expression is induced by ER stress through the protein kinase $\mathrm{R}$ (PKR)-like endoplasmic reticulum kinase (PERK) and inositol-requiring enzyme 1 (IRE1) pathways which enhance IL1 $\beta$ expression followed by its maturation through NLRP3 inflammation ${ }^{36,62}$. Since PERK is also a MERCs tether, whether its contribution resides in its tethering function or its ability to induce TXNIP expression needs clarification. Similarly, whether the modulation of the MERCs could hinder the activation of NLRP3 inflammasome is an interesting question that needs further consideration. In agreement with this possibility, silencing of the three human isoforms of the voltage-dependent anion channel (VDAC), another MERCs tether, severely reduced inflammasome activation and IL1 $\beta$ production ${ }^{40}$. This result could also be explained by the contribution of VDAC in mitochondrial $\mathrm{Ca}^{2+}$ overload and ROS production, the latter being an agonist of NLRP3-inflammasome. VDAC is also a docking factor for mitochondria-interacting proteins, such as the metabolic switch enzyme hexokinase and the anti-apoptotic protein $\mathrm{Bcl}-2$ and $\mathrm{Bcl}-\mathrm{X}_{\mathrm{L}}$ providing the cells with both metabolic advantage and resistance to apoptosis. This resistance to cell death results from the obstruction of VDAC channel cutoff by $\mathrm{Bcl}-2$ and $\mathrm{Bcl}-\mathrm{X}_{\mathrm{L}}$ decreasing mitochondrial $\mathrm{Ca}^{2+}$ entry and ROS production necessary for NLRP3 inflammasome activation and IL1 $\beta$ production $^{37,63,64}$. However, VDAC also interacts with Grp75 and the inositol-1,4,5-triphosphate receptor (IP3R) to 
actually physically tether the mitochondria to the ER (Fig. 1). Therefore, it is possible that silencing of VDAC also physically alters the localization and activation of the NLRP3-inflammosome at this site ${ }^{40}$.

Moreover, the identification of mitochondria antiviralsignaling protein (MAVS) as the docking site of the NLRP3 inflammasome at the MAM further confirmed the importance of MERCs in inflammation (Fig. 1) (55,66. $^{\text {. }}$ Interestingly, MAVS belongs to the mitochondrial antiviral response machinery involved in the production of type I interferons (IFNs) and pro-inflammatory cytokines ${ }^{67}$. In fact, upon infection, viral uncapped $5^{\prime}$-triphosphate end RNA and long double-stranded RNA are detected respectively by retinoic acid-inducible protein I (RIG-I) and melanoma differentiation-associated gene-5 (MDA-5) ${ }^{68-70}$, two cytosolic PRR with helicases and ATPase activity which discriminate the viral RNA from the abundant host RNA in the cytoplasm ${ }^{71,72}$. The binding of viral RNA triggers a conformational change in RIG I and MDA-5 that allows their interaction with MAVS at the MAM ${ }^{65}$. Their activation and translocation to the MERCs initiate signaling pathways that lead to the synthesis of multiple cytokines which include type I interferon (IFN) $)^{65,67,73,74}$. Interestingly, it was also reported that MAVS constitutively interacts with mitofusin 2 (MFN2), another MERCs tether, leading to the inhibition of inflammatory cytokine production. This suggests that the relocation of this antiviral response platform at the MERCs plays a complex regulatory role ${ }^{72,75}$ and as a whole, provide direct evidence of the involvement of MERCs in the establishment of a physiological inflammatory reaction as part of the innate immune response (Fig. 1 and Table 1). Further understanding of the spatiotemporal coordination of this inflammatory protein network and its regulation by MERCs is critical to therapeutically tailor inflammation as required.

\section{MERCs and leukocyte migration}

One key features of leukocytes is their ability to migrate throughout the organism. To illustrate this point, inflammation recruits hordes of neutrophils which massively infiltrate the site of infection to kill the invading bacteria $^{76,77}$. Moreover, the activation of resident macrophages and dendritic cells by the PAMP and DAMP increases their ability to migrate to the closest draining lymph node where they will present the antigenic material to the naive $B$ and $T$ lymphocytes ${ }^{78-85}$. Then, these activated lymphocytes migrate to the site of infection to neutralize the infected cells; therefore, migration is a necessity for the proper function of both innate and adaptive immune cells. Interestingly, leukocyte migration requires drastic reorganization of their cytoskeleton and mitochondrial network $^{86,87}$. 
Mitochondria are versatile organelles with a wellestablished role in cellular energy production and metabolism, $\mathrm{Ca}^{2+}$ homeostasis, cell cycle regulation, differentiation, cell death and aging ${ }^{88-93}$. Mitochondria are constantly remodeled by fusion and fission events which are regulated by a family of dynamin-related GTPases and their adaptor proteins. Mitofusin (MFN) 1 and 2 and optic atrophy 1 (OPA1) regulate outer and inner mitochondrial membrane fusion, respectively ${ }^{94-100}$. Mitochondrial fission is mediated by cytosolic dynamin-related protein 1 (DRP1) docking on its adaptor proteins Fis1, mitochondrial fission factor (MFF) and mitochondrial dynamics 51 and $49 \mathrm{kDa}$ proteins (MiD51 and MiD49) on the outer mitochondrial membrane ${ }^{101-107}$. Mitochondria can respond to many cellular cues such as starvation, stressinduced depolarization and cell death ${ }^{94,95,98,99,106,108-116}$.

Interestingly, it was shown that during leukocyte migration there is a redistribution of the mitochondria at the cell uropods in a mitochondrial fission- and calciumdependent manner ${ }^{86,87,117,118}$. Mitochondrial fission facilitates their relocation and promotes lymphocyte chemotaxis, whereas mitochondrial fusion inhibits both processes probably due to the inability to transport too large organelles along the cytoskeleton ${ }^{86,87,117-119}$. Interestingly, both mitochondrial fission and cellular $\mathrm{Ca}^{2+}$ homeostasis are regulated by MERCs (Figs. 1, 2 and Table 1) ${ }^{11,14,18,20,22,27}$. At the MERCs defined by the ER tubules wrapping the mitochondria, the mitochondria are constricted $^{3,11}$. It was also proposed that these MERCs provide a platform for the recruitment of motor generating force cytoskeletal proteins ${ }^{3}$. In fact, ER-bound inverted formin 2 (INF2) concentrates between the two organelles where ER wraps the mitochondria (Fig. 1) $)^{3,20,120}$. The INF2 triggers the assembly of the actomyosin motor providing the force for the initial constriction of the mitochondria ${ }^{3,11,20,120}$. Once assembled, the ER-associated constricted mitochondria enable polymerized DRP1 to spiral around the mitochondria to mediate their fission ${ }^{3,11,20,101,102,106,120}$. Moreover, mitochondrial movement along microtubules is regulated by calcium oscillation-dependent Miro-Milton complex interaction with kinesin motor ${ }^{117,121-124}$. Interestingly, Miro is an outer mitochondrial membrane protein enriched at the MERC ${ }^{123,125}$. It interacts with dynein through the cytosolic factor Milton giving molecular insight into how calcium regulates the mitochondrial redistribution that also occurs during cell migration ${ }^{122,126,127}$.

Similarly, MERCs also play an important role in intracellular calcium homeostasis. Actually, the regulation of mitochondrial calcium uptake is the best described MERCs function so far. In resting condition, $\mathrm{Ca}^{2+}$ level ranges from nanomolar to micromolar concentration in the cytosol and the mitochondria, respectively, while it is in the half millimolar range in the $\mathrm{ER}^{93}$. This asymmetric calcium distribution is tightly regulated by a variety of calcium channels, pumps and exchangers expressed at the plasma membrane, the ER, and the mitochondria $^{14,22,43,46,47,128-134}$. The coordination of the different calcium pools relies on membrane contact sites between the ER and the plasma membrane, and between the ER and mitochondria, thus acting as signaling platforms to ensure synchronized activities of $\mathrm{Ca}^{2+}$ channels, pumps and exchangers $3,12,43,46,47,128,131-134$. Upon activation, phospholipase C (PLC) produces inositol-1,4,5-triphosphate (IP3) from plasma membrane phosphatidylinositol-4,5 diphosphate ${ }^{135,136}$. The IP3 triggers ER $\mathrm{Ca}^{2+}$ release through a channel formed at the ER membrane by the IP3 receptor (IP3R) $)^{135,136}$. This IP3R-mediated ER calcium release is buffered by mitochondrial $\mathrm{Ca}^{2+}$ uptake through VDAC and the mitochondrial $\mathrm{Ca}^{2+}$ uniporter (MCU), located in the outer and inner mitochondrial

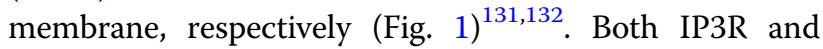
VDAC are concentrated at ER-mitochondria contact sites where they also contribute to tether these two organelles together (Fig 1) ${ }^{3,12}$. The $75 \mathrm{kDa}$ glucose-regulated protein (GRP75) interacts with both IP3R and VDAC to reinforce and increase the coupling of these two ion channels (Fig 1) $3,12,137$. This ER-mitochondria $\mathrm{Ca}^{2+}$ shuttling is regulated by a supramolecular weight protein complex including AKT kinase, promyelocytic leukemia (PML) and the serine threonine phosphatase PP2A enriched in the $\mathrm{MAM}^{138-140}$. Moreover, the vesicle-associated membrane protein-associated protein B (VAPB), an integral ER protein whose amino-terminus projects into the cytosol, interacts with the outer mitochondrial membrane protein tyrosine phosphatase-interacting protein 51 (PTPIP51) to favor the ER-mitochondria $\mathrm{Ca}^{2+}$ exchange (Fig. 1) ${ }^{141}$. The apposition of the ER with the mitochondria at these contact sites forms a confined space enabling to build-up local $\mathrm{Ca}^{2+}$ microdomains. These $\mathrm{Ca}^{2+}$ microdomains reach concentration compatible with MCU' low affinity in order to ensure mitochondrial calcium uptake. This mitochondrial calcium uptake is necessary for activation of TCA dehydrogenase involved in ATP production and in the regulation of cell death ${ }^{28,142-146}$. Together, this indicates that MERCs, by their ability to regulate mitochondrial fission and calcium homeostasis, can modulate leukocyte migration and function (Table 1 and Fig. 2).

\section{MERCs and antigen presentation}

Dendritic cells (DCs), macrophages and B cells are professional antigen presenting cells (APC) as they excel in the ability to ingest and process antigenic material to present in the context of their major histocompatibility complex class I (MHC-I) or class II (MHC-II) molecules in order to activate cytotoxic $\mathrm{CD}^{+} \mathrm{T}$ cells or $\mathrm{CD} 4^{+}$ helper $\mathrm{T}$ cells, respectively ${ }^{78,79,147-149}$. The mechanism of 


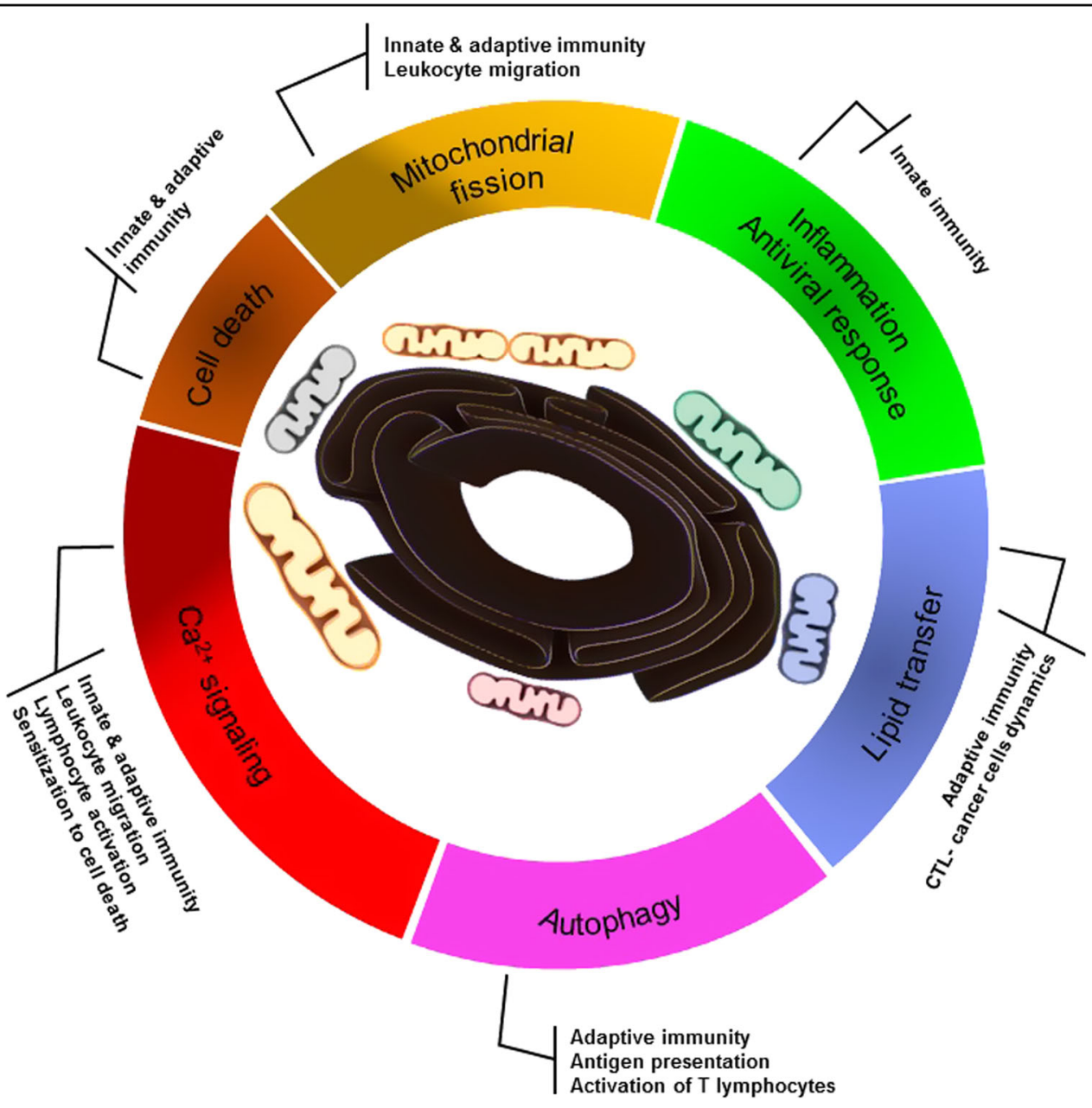

Fig. 2 Wheel shaped representation of MERCs functions and their immunological involvement. In the center, ER (black) interacts with different shaped mitochondria to form MERCs. Wheel display of the corresponding cell biology functions involving the MERCs, e.g., calcium signaling (red), cell death (dark orange), mitochondrial fission (yellow), inflammation and antiviral response (green), lipid transfer (purple) and autophagy (pink). Note in the vicinity of the cell death segment, the segment representing calcium signaling and mitochondrial fission are darkened to indicate the gray area where calcium signaling and mitochondrial fission crosstalk with cell death. These MERCs cell biology functions are connected to the physiological immunological processes they are susceptible to regulate.

antigen presentation has been reviewed in detail elsewhere $^{148,149}$. Conventionally, MHC-I molecules are normally loaded with peptides derived from cytosolic proteolysis, while MHC-II molecules are loaded with peptides from extracellular pathogens that have been phagocytosed $^{148,149}$. When DCs are directly infected with viruses, they generate MHC-I antigenic peptides by the classical pathway. However, in situations where the DCs are not directly infected or in case of tumors and allogeneic transplants, the antigens are internalized by phagocytosis of microbes, infected, allogeneic or transformed dying cells and cross-presented on the MHC-I of the $\mathrm{DCs}^{148-151}$. Interestingly, autophagy potentiates both MHC-I, MHC-II antigen presentation and MHC-I crosspresentation, the latter being seen when the autophagic process is triggered in donor cells ${ }^{152-160}$. Autophagy is also critical for the survival, differentiation and function of $\mathrm{T}$ lymphocytes and therefore plays an important role in the immune response ${ }^{161,162}$. There are at least three different types of autophagy, including macroautophagy (usually simply referred as autophagy), chaperonemediated autophagy and micro-autophagy ${ }^{163}$. Autophagy is the process by which cytosolic components and organelles are segregated in a double membrane neocompartment, the autophagosome, for degradation and recycling following autophagosome fusion with lysosomes ${ }^{157,164}$. Nutrient deprivation is a potent inducer of autophagy through the inhibition of the mammalian target of rapamycin (mTOR) ${ }^{165,166}$. This leads to the activation and relocation of mTOR substrates ULK1/2, ATG13 and FIP200 from the cytosol to certain domains of the ER and the subsequent recruitment of the class III 
phosphatidylinositol kinase (class III-PI3K) complex VPS34/VPS15/beclin 1 and ATG14 to the ER ${ }^{163,167-171}$. The autophagosome formation also requires ATG12ATG5 and the phosphatidylethanolamine (PE)-conjugated ATG8/LC3, GATE16, and GABARAP two ubiquitin-like conjugating systems ${ }^{163,172-176}$. It is suggested that the ER is crucial for the initiation of the autophagosome formation which takes place at the contact site between the ER and the mitochondria ${ }^{19,177}$. Moreover, upon starvation, the pre-autophagosome marker ATG14 is redistributed at MERCs while ATG5 also localizes at this site until autophagosome formation is completed $^{19}$. Strikingly, starvation also triggers an increase in MERCs length ${ }^{17}$. Whether this increase in MERCs length could be a mechanism to modulate autophagy and the dependent antigen presentation needs to be addressed. Taken together, the critical importance of autophagy during antigen presentation could suggest that MERCs are likely critical regulators of lymphocyte activation as they contribute to autophagosome biogenesis (Table 1 and Fig. 2).

\section{MERCs and lymphocyte activation}

Engagement of the B-cell receptor (BCR) or the T-cell receptor (TCR) and their respective co-receptors triggers an intracellular phosphorylation cascade culminating in the activation of the transcription factors AP1, NF- $\mathrm{KB}$, NFAT, OCA-B/OBF-1 and Pip/IRF-4 that are critical for $\mathrm{B}$ and $\mathrm{T}$ lymphocyte activation, respectively ${ }^{31,178-182}$. One common feature of lymphocyte activation is the recruitment and activation of phospholipase $\mathrm{C} \gamma$ (PLC $\gamma)$

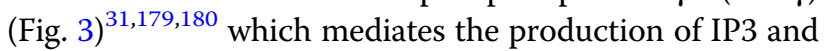
diacylglycerol (DAG). The DAG activates protein kinase $\mathrm{C}$ (PKC) initiating a phosphorylation cascade ending with the activation of the transcription factor NF- $\mathrm{KB}$ (Fig. 3) ${ }^{183-186}$. The IP3 induces a rapid increase in intracellular $\mathrm{Ca}^{2+}$ levels by means of activation of stores operating calcium (SOC) influx following IP3R-mediated ER calcium store release and activation of calcium-release activated calcium (CRAC) channel $^{43,46,47,133-136}$. Cytosolic $\mathrm{Ca}^{2+}$ binds to calmodulin to activate the phosphatase calcineurin. Active calcineurin/calcium/calmodulin complex dephosphorylates and activates the transcription factor nuclear factor of activated $\mathrm{T}$ cells (NFAT) ${ }^{31,44}$. Since intracellular $\mathrm{Ca}^{2+}$ flux is essential for lymphocyte activation, any biological processes impeding on this $\mathrm{Ca}^{2+}$ homeostasis can impact lymphocyte activation. For example, phosphoenol pyruvate (PEP), by repressing the activity of sarco/ER $\mathrm{Ca}^{2+}$-ATPase (SERCA) whose function is to pump $\mathrm{Ca}^{2+}$ back into the ER, sustains TCRmediated $\mathrm{Ca}^{2+}$-NFAT signaling and potentiates $\mathrm{T}$ cell activation ${ }^{187,188}$. Interestingly, mitochondria buffer the inflowing $\mathrm{Ca}^{2+}$ and prevent the blunting of the CRAC $\mathrm{Ca}^{2+}$ allowing full activation of $\mathrm{T}$ cells ${ }^{87,189}$. As discussed earlier, MERCs are particularly involved in the modulation of the cellular $\mathrm{Ca}^{2+}$ homeostasis; this suggests that MERCs most likely play a critical role in modulating lymphocytes activation (Table 1 and Figs. 2, 3). As already stated, mitochondrial $\mathrm{Ca}^{2+}$ overload sensitizes cells to death (Fig. 2 darkened zone of the calcium signaling segment) $22,146,189-193$. Furthermore, the interaction of the outer mitochondrial membrane protein Fis1 with the ER protein Bap31 constitutes an additional MERC tether, whose function is to provide a platform for apoptosis induction (Fig. 1) ${ }^{28,194-196}$. This suggests that MERCs could also act on lymphocyte homeostasis by regulating their development during negative selection and their elimination after antigen-dependent peripheral expansion in the process called activation induced cell death (AICD) (Table 1 and Fig. 2). Both processes involve massive lymphocyte death ${ }^{42,197-199}$.

\section{MERCs and the cytotoxic anticancer response}

The role of the immune system against cancer was only demonstrated as primary and acquired immunodeficiency are associated with increased susceptibility to cancer ${ }^{200-}$ 203. Furthermore, the size of the immune infiltrate in primary tumor is a good prognosis for patient survival, explaining why blockage of immune checkpoint receptors CTLA4 and PD-1 is a very promising immunotherapy strategy ${ }^{202,204-208}$. Further supporting the importance of the anti-tumoral immunity, it was shown that among 810 mutant mouse lines screened to identify microenvironmental regulators of metastatic colonization, only 23 genes were important among which 19 have immune function ${ }^{209}$. Nevertheless, the occurrence of cancers is a direct demonstration that tumor cells are capable of evading the immune surveillance ${ }^{202,210-213}$. This ability to escape immune recognition and elimination is now a new hallmark of cancer ${ }^{214}$.

Strikingly, cancer cell plasma membrane topography and glycocalyx regulate the ability of cytotoxic lymphocytes to contact them ${ }^{215,216}$. To trigger apoptosis, cytotoxic lymphocytes must form an immunological synapse with their cancer target cells into which they degranulate their cytotoxic granule content ${ }^{45,179,217-223}$. We found this pathway to also be dependent on target cell mitochondrial ROS production ${ }^{219-222,224}$. Using a glioblastoma multiform model, a very aggressive primary malignant brain tumor, we found that surface glycan expression regulates these cancer cells engagement by cytotoxic lymphocytes ${ }^{225,226}$. In fact, the glioma stemlike cells (GSC) which expressed lower surface sialylated glycans were more susceptible to cytotoxic lymphocytes as opposed to the glioma differentiated cells (GDC)

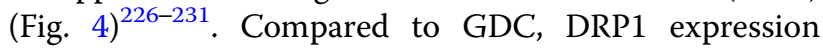
was higher in GSC, while MFN2 expression was reduced, explaining their fragmented mitochondrial 


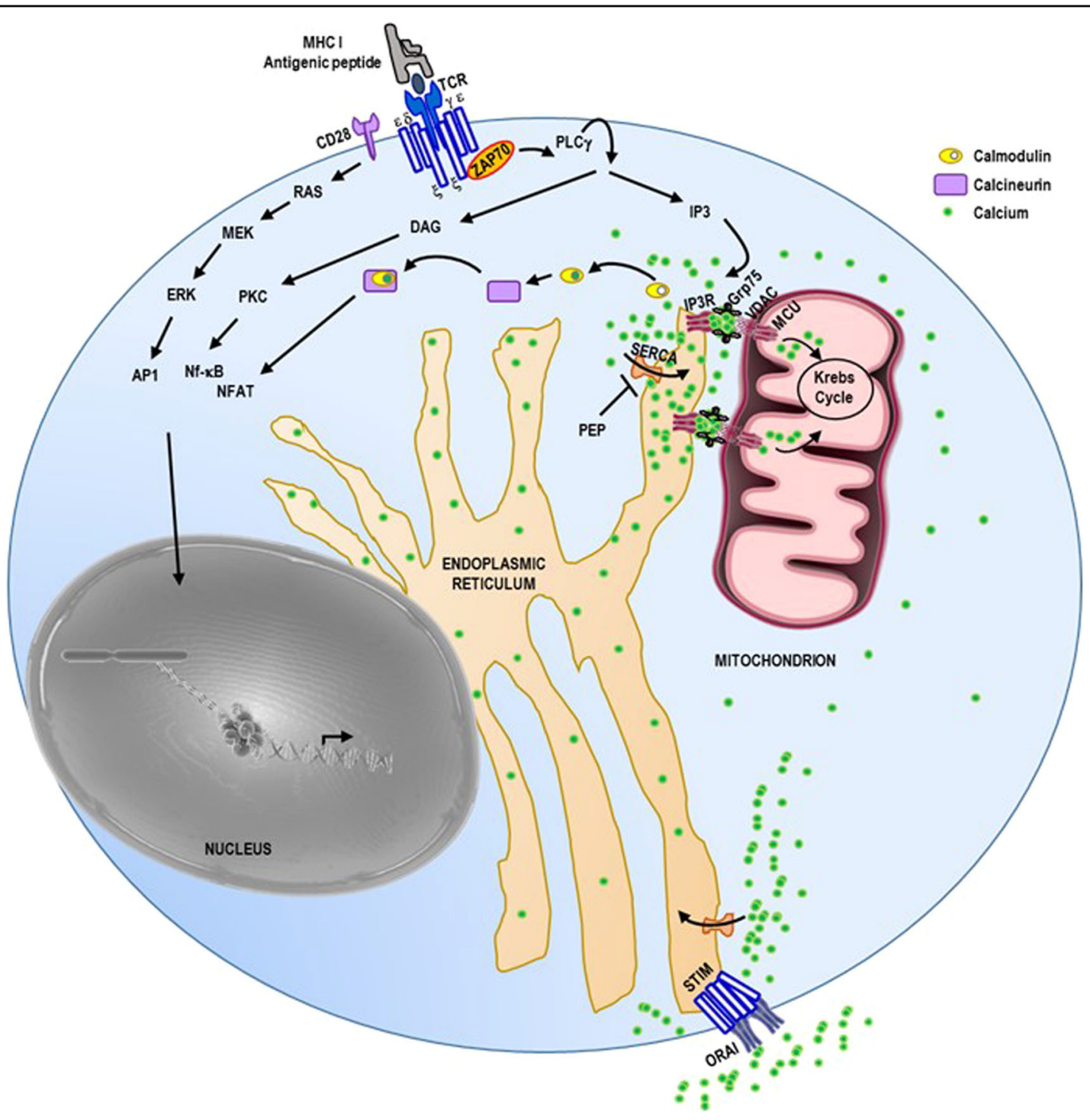

Fig. 3 MERCs and calcium signaling during T cell activation. Cytotoxic T cells receive antigenic stimulation from MHC I antigenic peptide complexes at the surface of target cells (not represented) through its TCR CD3 complex. This triggers a signaling cascade inducing the activation of the kinase ZAP70 which activates phospholipase PLCY. Active PLC $\gamma$ hydrolyzes membrane phosphatidylinositol 4,5-bisphosphate into IP3 and diacylglycerol (DAG). DAG activates protein kinase C (PKC) which then activates the transcription factor NF-KB. IP3 binds to the IP3R on the endoplasmic reticulum (ER) to trigger calcium $\left(\mathrm{Ca}^{2+}\right)$ release. In the cytosol, calcium binds to calmodulin and the complex $\mathrm{Ca}^{2+} / \mathrm{calmodulin}$ activates the phosphatase calcineurin leading to the activation of the transcription factor NFAT. The engagement of CD28 co-receptor at the surface of the T lymphocyte will trigger RAS, MEK, and ERK kinase cascade ultimately leading to AP1 transcription factor activation. The NFAT, NF-KB and AP1 enter the nucleus where they activate the expression of a subset of genes encoding for proteins involved in T lymphocyte proliferation, differentiation and effector function. The ER calcium depletion is sensed by STIM that in turn activates the plasma membrane calcium channel Orai which allows extracellular calcium to enter the cytosol. The ER calcium pump SERCA will pump calcium from the cytosol back into the ER. The MERC tether IP3R/ VDAC/Grp75 allows the formation of microdomains of high- $\mathrm{Ca}^{2+}$ concentration for mitochondrial uptake through the mitochondrial calcium uniporter (MCU). In this case, this mitochondrial calcium uptake, by buffering the cytosolic calcium, may modulate the activation threshold of the T lymphocyte. Likewise, by inhibiting SERCA, phosphoenol pyruvate (PEP) reduces T lymphocyte activation threshold. $\varepsilon, \delta, \gamma, \xi$ are the subunits of the CD3 complex providing signaling module to the T-cell receptor.

phenotype ${ }^{226,232}$. MFN2 was the only MERCs tether whose expression was significantly reduced in GSC as opposed to GDC ${ }^{28,137,141,233,234}$, in agreement with GSC shorter mitochondria poorly interacting with the ER, than did the elongated mitochondria in GDC.
Consequently, after stimulation, GSC experienced reduced mitochondrial $\mathrm{Ca}^{2+}$ uptake as compared to their GDC counterparts. Excitingly, restoring the ERmitochondria contact in GSC with an artificial tether was sufficient to restore the surface expression of certain 


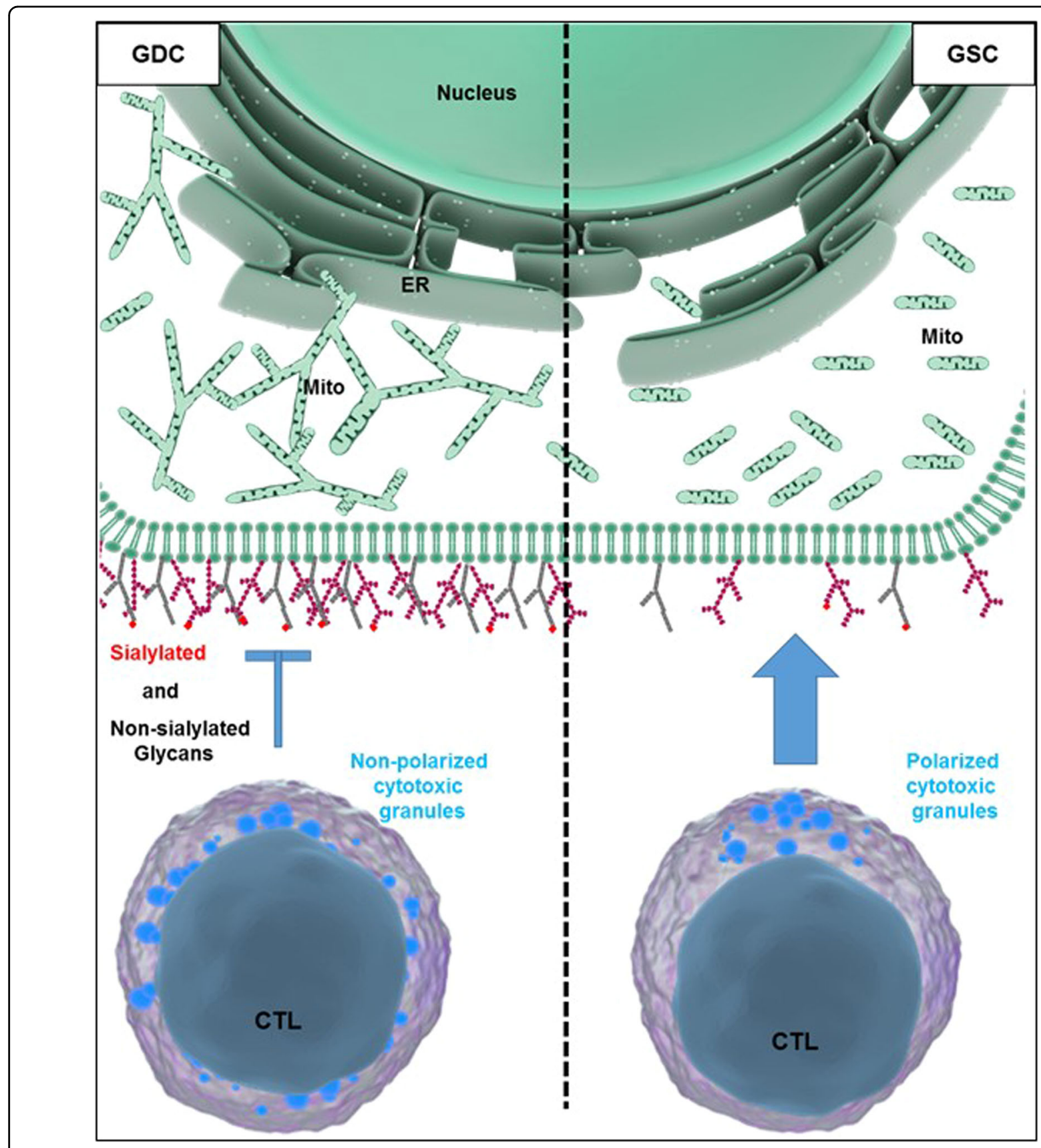

Fig. 4 Mitochondria morphology and dynamism regulate glioma surface glycan expression and sensitivity to cytotoxic lymphocytes mediated killing. On the left, glioma differentiated cells (GDC) have reticulated long mitochondria that interact well with the ER to form MERCs, leading to a high-surface expression of some glycans, impeding engagement and killing by cytotoxic lymphocytes. On the right, glioma stemlike cells have short and highly dynamic mitochondria that make less MERCs, resulting in a lower surface expression of glycans, better engagement and killing by cytotoxic lymphocytes. ER, endoplasmic reticulum; Mito, mitochondria

sialylated glycans and reduce their susceptibility to cytotoxic lymphocyte-mediated killing (Fig. 4) ${ }^{226}$.

Protein and lipid glycosylation are critical for cell physiology ${ }^{235-237}$. Changes in glycosylation and the expression level of surface sialic acid and sialyltransferase are directly correlated with tumor metastasis ${ }^{238-240}$.
Interestingly, MAM is enriched in glycosyltransferases and ceramide synthase activities ${ }^{241-243}$. Moreover, in addition to the vesicular transport system, the exchanges and the biosynthesis of lipids also require MERCs $^{3,21,244,245}$. In yeast, the ERMES complex at the MERCs is composed of Mmm1, Mdm10, Mdm12, and 
Mdm34 that are functionally connected to phospholipid biosynthesis ${ }^{21,244,246}$. During their biosynthesis, lipids commute back and forth between ER and mitochondria at membrane contact sites. In the ER, phosphatidic acid is converted to phosphatidylserine which is further decarboxylated in the mitochondria inner membrane to form phosphatidylethanolamine. Phosphatidylethanolamine shuttles back to the ER where it is transformed into

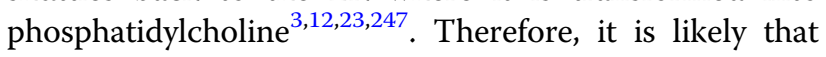
the MERCs defects observed in GSC could result in an altered biosynthesis or bioavailability of lipids, essential for the surface expression of some glycolipids. In future studies, it would be very important to test whether MERCs dysregulation is a novel feature of cancer stemlike cells regardless of their histological origin.

\section{MERCs and human diseases}

MERCs may be a novel regulatory hub for cancer development through the recruitment of proto-oncogenes and tumor suppressor ${ }^{15}$. Indeed, extra nuclear accumulation of the tumor suppressor PML at the MERCs, where it forms a supramolecular weight complex with PP2A and AKT, provides a regulatory module for the ERmitochondrial $\mathrm{Ca}^{2+}$ transfer apparatus ${ }^{140,248}$. This localization of a pool of PML is essential for the propagation of apoptotic stimuli following mitochondrial $\mathrm{Ca}^{2+}$ overload in conditions of cellular stress ${ }^{140,248}$. Similarly, PTEN, another tumor suppressor, is also enriched at MAM where it also regulates AKT-dependent phosphorylation of IP3R and ER-mitochondria $\mathrm{Ca}^{2+}$ shuttling. Interestingly, at the MERCs, mTORC2 interacts with the IP3R/ Grp75/VDAC1 to regulate not only MAM's integrity but also mitochondrial ATP production in a manner that relies on Akt-mediated phosphorylation of IP3R, Hexokinase 2, and phosphofurin acidic cluster sorting protein 2 (PACS2) equipping the MERCs with control over cellular growth and metabolism ${ }^{15,249}$. Interestingly, PACS2 which is also a MERCs tether, is mutated in $40 \%$ of sporadic colorectal cancer patient ${ }^{250,251}$.

Correct protein folding in the ER needs proper disulfide bond formation by oxidoreductin 1 (ERO1) $\alpha$ and proteindisulfide isomerase (PDI ${ }^{252}$. Interestingly, ERO1 $\alpha$ interacts with ERp44, a negative regulator of IP3Rs (Fig. 1) and ERO1 $\alpha$ expression is independently regulated by both hypoxia and hypoglycemia, two known microenvironmental factors associated with cancer development ${ }^{253,254}$. In the same manner, it was also elegantly demonstrated in vivo using a postprandial model that inhibition of mTORC1signaling pathway leads to a doubling in MERCs length ${ }^{17}$; this indicates that nutrient abundance can regulate all the cellular functions where MERCs play a role. These results explain how cancer cells, by outcompeting tumor infiltrating $\mathrm{T}$ lymphocyte for glucose in the microenvironment can both inhibit the anti-cancer cytotoxic immune response while adapting to this microenvironment for cancer progression ${ }^{17,187,188}$. As a whole, these results explain how the tumor microenvironment could impede the structure and function of MERCs to promote cancer progression. Moreover, since MERCs regulate ER-mitochondria $\mathrm{Ca}^{2+}$ interplay and apoptosis, it is very likely that MERCs could also modulate cancer cells sensitivity to chemotherapy and the cooccurrence of the beneficial immunogenic cell death $(\mathrm{ICD})^{255}$. The ICD also relies on the ability of dendritic cells to present antigen from the dying tumor cells to Tlymphocyte populations (see MERCs and antigen presentation). So, whether through the modulation of sensitivity to, type of cell death or through antigen presentation, MERCs are likely involved in the eradication of cancer cells.

MERCs regulate many important biological processes, the dysregulation of which can severely affect cell homeostasis and consequently human health. Inflammation is a good illustration of such a process through which MERCs alteration may contribute to other human diseases, such as neurodegeneration, diabetes, and cardiovascular diseases $4,13,15,256,257$. For more information I invite the readers to PMID:25557408; 24642268, and 24316057.

\section{Conclusion}

The necessity to isolate biochemical reactions impose the cell compartmentalization with the consequence of restricting the mutualisation of essential constituents. To overcome this restriction, the different cell compartments communicate at a contact zone, defined as organelle membrane contact sites. The ER is the largest cell network that not surprisingly touches many other organelles, including the mitochondria. Mitochondria-ER contact sites (MERCs) play critical functions, such as lipid transfer, initiation of autophagosome formation, determination of the mitochondrial fission site, mitochondrial $\mathrm{Ca}^{2+}$ homeostasis, as well as apoptosis ${ }^{11,14,18-28}$. As we have seen, many of these functions are important for both innate and adaptive immunity. Actually, because of the different challenges immune cells must face to protect the organism from invading pathogens, they represent good models to further investigate the MERCs structurally, biochemically, and functionally. These investigations are expected to provide additional important insight into the role of these dynamic membrane interactions in the pathophysiology of the immune system.

\section{Acknowledgements}

This work was supported by a Subsidy from Foundation Privée des HUG, ERC starting grant ERC-2010-StG_20091118 and Foundation Boninchi. I thank Dr. Jerome Thiery for proofreading this manuscript.

Conflict of interest

The author declares that they have no conflict of interest. 


\section{Publisher's note}

Springer Nature remains neutral with regard to jurisdictional claims in published maps and institutional affiliations.

Received: 10 July 2017 Revised: 25 November 2017 Accepted: 28 November 2017

Published online: 28 February 2018

\section{References}

1. Gardner, B. M. \& Walter, P. Unfolded proteins are Ire1-activating ligands that directly induce the unfolded protein response. Science 333, 1891-1894 (2011).

2. Lu, M. et al. Opposing unfolded-protein-response signals converge on death receptor 5 to control apoptosis. Science 345, 98-101 (2014).

3. Phillips, M. J. \& Voeltz, G. K. Structure and function of ER membrane contact sites with other organelles. Nat. Rev. Mol. Cell Biol. 17, 69-82 (2016).

4. Giorgi, C. et al. Mitochondria-associated membranes: composition, molecular mechanisms, and physiopathological implications. Antioxid. Redox Signal. 22, 995-1019 (2015).

5. Csordas, G. et al. Structural and functional features and significance of the physical linkage between ER and mitochondria. J. Cell Biol. 174, 915-921 (2006).

6. Giorgi, C., De Stefani, D., Bononi, A., Rizzuto, R. \& Pinton, P. Structural and functional link between the mitochondrial network and the endoplasmic reticulum. Int. J. Biochem. Cell Biol. 41, 1817-1827 (2009).

7. Mannella, C. A., Buttle, K., Rath, B. K. \& Marko, M. Electron microscopic tomography of rat-liver mitochondria and their interaction with the endoplasmic reticulum. Biofactors 8, 225-228 (1998).

8. Meier, P. J., Spycher, M. A. \& Meyer, U. A. Isolation and characterization of rough endoplasmic reticulum associated with mitochondria from normal rat liver. Biochim. Biophys. Acta 646, 283-297 (1981).

9. Shore, G. C. \& Tata, J. R. Two fractions of rough endoplasmic reticulum from rat liver. I. Recovery of rapidly sedimenting endoplasmic reticulum in association with mitochondria. J. Cell Biol. 72, 714-725 (1977).

10. Ogata, T. \& Yamasaki, Y. Ultra-high-resolution scanning electron microscopy of mitochondria and sarcoplasmic reticulum arrangement in human red, white, and intermediate muscle fibers. Anat. Rec. 248, 214-223 (1997).

11. Friedman, J. R. et al. ER tubules mark sites of mitochondrial division. Science 334, 358-362 (2011).

12. Helle, S. C. et al. Organization and function of membrane contact sites, Biochim. Et. Biophys. Acta 1833, 2526-2541 (2013).

13. Giacomello, M. \& Pellegrini, L. The coming of age of the mitochondria-ER contact: a matter of thickness. Cell Death Differ. 23, 1417-1427 (2016).

14. Rizzuto, R. et al. Close contacts with the endoplasmic reticulum as determinants of mitochondrial Ca2+ responses. Science 280, 1763-1766 (1998).

15. van Vliet, A. R., Verfaillie, T. \& Agostinis, P. New functions of mitochondria associated membranes in cellular signaling. Biochim. Biophys. Acta $\mathbf{1 8 4 3}$ 2253-2262 (2014).

16. Bravo, R. et al. Increased ER-mitochondrial coupling promotes mitochondrial respiration and bioenergetics during early phases of ER stress. J. Cell Sci. 124 2143-2152 (2011).

17. Sood, A. et al. A Mitofusin-2-dependent inactivating cleavage of Opa1 links changes in mitochondria cristae and ER contacts in the postprandial liver. Proc. Natl Acad. Sci. USA 111, 16017-16022 (2014)

18. Rowland, A. A. \& Voeltz, G. K. Endoplasmic reticulum-mitochondria contacts: function of the junction. Nat. Rev. Mol. Cell Biol. 13, 607-625 (2012).

19. Hamasaki, M. et al. Autophagosomes form at ER-mitochondria contact sites. Nature 495, 389-393 (2013).

20. Korobova, F., Ramabhadran, V. \& Higgs, H. N. An actin-dependent step in mitochondrial fission mediated by the ER-associated formin INF2. Science 339, 464-467 (2013)

21. Kornmann, B. et al. An ER-mitochondria tethering complex revealed by a synthetic biology screen. Science 325, 477-481 (2009).

22. Rizzuto, R., Brini, M., Murgia, M. \& Pozzan, T. Microdomains with high Ca2+ close to IP3-sensitive channels that are sensed by neighboring mitochondria. Science 262, 744-747 (1993).

23. Stone, S. J. \& Vance, J. E. Phosphatidylserine synthase- 1 and -2 are localized to mitochondria-associated membranes. J. Biol. Chem. 275, 34534-34540 (2000).
24. Piccini, M. et al. FACL4, a new gene encoding long-chain acyl-CoA synthetase 4 , is deleted in a family with Alport syndrome, elliptocytosis, and mental retardation. Genomics 47, 350-358 (1998).

25. Rusinol, A. E., Cui, Z., Chen, M. H. \& Vance, J. E. A unique mitochondriaassociated membrane fraction from rat liver has a high capacity for lipid synthesis and contains pre-Golgi secretory proteins including nascent lipoproteins. J. Biol. Chem. 269, 27494-27502 (1994).

26. Thomson, M. Does cholesterol use the mitochondrial contact site as a conduit to the steroidogenic pathway? Bioessays 25, 252-258 (2003).

27. Hayashi, T., Rizzuto, R., Hajnoczky, G. \& Su, T. P. MAM: more than just a housekeeper. Trends Cell Biol. 19, 81-88 (2009).

28. Iwasawa, R., Mahul-Mellier, A. L., Datler, C., Pazarentzos, E. \& Grimm, S. Fis1 and Bap31 bridge the mitochondria-ER interface to establish a platform for apoptosis induction. EMBO J. 30, 556-568 (2011).

29. Chaplin, D. D. Overview of the immune response. J. Allergy Clin. Immunol. 125, S3-S23 (2010)

30. Turvey, S. E. \& Broide, D. H. Innate immunity. J. Allergy Clin. Immunol. 125 S24-S32 (2010)

31. Bonilla, F. A. \& Oettgen, H. C. Adaptive immunity. J. Allergy Clin. Immunol. 125 S33-S40 (2010).

32. Atarashi, $\mathrm{K}$. et al. Induction of colonic regulatory $\mathrm{T}$ cells by indigenous Clostridium species. Science 331, 337-341 (2011).

33. Lee, Y. K. \& Mazmanian, S. K. Has the microbiota played a critical role in the evolution of the adaptive immune system? Science 330, 1768-1773 (2010).

34. Janeway, C. A. Jr. Approaching the asymptote? Evolution and revolution in immunology. Cold Spring Harb. Symp. Quant. Biol. 54, 1-13 (1989).

35. Bianchi, M. E. DAMPs, PAMPs and alarmins: all we need to know about danger. J. Leukoc. Biol. 81, 1-5 (2007).

36. Lerner, A. G. et al. IRE1alpha induces thioredoxin-interacting protein to activate the NLRP3 inflammasome and promote programmed cell death under irremediable ER stress. Cell Metab. 16, 250-264 (2012).

37. Marchi, S., Patergnani, S. \& Pinton, P. The endoplasmic reticulummitochondria connection: one touch, multiple functions. Biochim. Biophys. Acta 1837, 461-469 (2014).

38. Saxena, G., Chen, J. \& Shalev, A. Intracellular shuttling and mitochondrial function of thioredoxin-interacting protein. J. Biol. Chem. 285, 3997-4005 (2010)

39. Zhou, R., Tardivel, A., Thorens, B., Choi, I. \& Tschopp, J. Thioredoxin-interacting protein links oxidative stress to inflammasome activation. Nat. Immunol. 11, 136-140 (2010).

40. Zhou, R., Yazdi, A. S., Menu, P. \& Tschopp, J. A role for mitochondria in NLRP3 inflammasome activation. Nature 469, 221-225 (2011).

41. Alder, M. N. et al. Diversity and function of adaptive immune receptors in a jawless vertebrate. Science 310, 1970-1973 (2005).

42. Wardemann, H. et al. Predominant autoantibody production by early human B cell precursors. Science 301, 1374-1377 (2003).

43. Feske, S. et al. A mutation in Orai1 causes immune deficiency by abrogating CRAC channel function. Nature 441, 179-185 (2006)

44. Hogan, P. G., Chen, L., Nardone, J. \& Rao, A. Transcriptional regulation by calcium, calcineurin, and NFAT. Genes Dev. 17, 2205-2232 (2003).

45. Kummerow, $\mathrm{C}$. et al. The immunological synapse controls local and global calcium signals in T lymphocytes. Immunol. Rev. 231, 132-147 (2009).

46. Yeromin, A. V. et al. Molecular identification of the CRAC channel by altered ion selectivity in a mutant of Orai. Nature 443, 226-229 (2006).

47. Zhang, S. L. et al. STIM1 is a Ca2+ sensor that activates CRAC channels and migrates from the $\mathrm{Ca} 2+$ store to the plasma membrane. Nature 437, 902-905 (2005).

48. Cavazzana-Calvo, M. et al. Gene therapy of human severe combined immunodeficiency (SCID)-X1 disease. Science 288, 669-672 (2000).

49. Buckley, R. H. et al. Hematopoietic stem-cell transplantation for the treatment of severe combined immunodeficiency. N. Engl. J. Med. 340, 508-516 (1999).

50. Markert, M. L. et al. Transplantation of thymus tissue in complete DiGeorge syndrome. N. Engl. J. Med. 341, 1180-1189 (1999).

51. Alexopoulou, L., Holt, A. C., Medzhitov, R. \& Flavell, R. A. Recognition of double-stranded RNA and activation of NF-kappaB by Toll-like receptor 3. Nature 413, 732-738 (2001)

52. Hemmi, $\mathrm{H}$. et al. A Toll-like receptor recognizes bacterial DNA. Nature $\mathbf{4 0 8}$ 740-745 (2000)

53. Termeer, $\mathrm{C}$. et al. Oligosaccharides of Hyaluronan activate dendritic cells via toll-like receptor 4. J. Exp. Med. 195, 99-111 (2002). 
54. Poltorak, A. et al. Defective LPS signaling in C3H/HeJ and C57BL/10ScCr mice: mutations in Tlr4 gene. Science 282, 2085-2088 (1998).

55. Newton, K., Dixit, V. M. Signaling in innate immunity and inflammation. Cold Spring Harb. Perspect. Biol. 4, 2012.

56. Schroder, K. \& Tschopp, J. The inflammasomes. Cell 140, 821-832 (2010).

57. Mariathasan, S. et al. Cryopyrin activates the inflammasome in response to toxins and ATP. Nature 440, 228-232 (2006).

58. Yamasaki, K. et al. NLRP3/cryopyrin is necessary for interleukin-1beta (IL-1beta) release in response to hyaluronan, an endogenous trigger of inflammation in response to injury. J. Biol. Chem. 284, 12762-12771 (2009).

59. Halle, A. et al. The NALP3 inflammasome is involved in the innate immune response to amyloid-beta. Nat. Immunol. 9, 857-865 (2008).

60. Cruz, C. M. et al. ATP activates a reactive oxygen species-dependent oxidative stress response and secretion of proinflammatory cytokines in macrophages. J. Biol. Chem. 282, 2871-2879 (2007).

61. Dostert, $C$. et al. Innate immune activation through Nalp3 inflammasome sensing of asbestos and silica. Science 320, 674-677 (2008).

62. Oslowski, C. M. et al. Thioredoxin-interacting protein mediates ER stressinduced beta cell death through initiation of the inflammasome. Cell Metab. 16, 265-273 (2012)

63. Arbel, N. \& Shoshan-Barmatz, V. Voltage-dependent anion channel 1-based peptides interact with $\mathrm{BCl}-2$ to prevent antiapoptotic activity. J. Biol. Chem. 285, 6053-6062 (2010).

64. Shoshan-Barmatz, V. \& Mizrachi, D. VDAC1: from structure to cancer therapy. Front. Oncol. 2, 164 (2012)

65. Horner, S. M. et al. Mitochondrial-associated endoplasmic reticulum membranes (MAM) form innate immune synapses and are targeted by hepatitis $C$ virus. Proc. Natl Acad. Sci. USA 108, 14590-14595 (2011).

66. Subramanian, N., Natarajan, K., Clatworthy, M. R., Wang, Z. \& Germain, R. N. The adaptor MAVS promotes NLRP3 mitochondrial localization and inflammasome activation. Cell 153, 348-361 (2013).

67. Seth, R. B., Sun, L., Ea, C. K. \& Chen, Z. J. Identification and characterization of MAVS, a mitochondrial antiviral signaling protein that activates NF-kappaB and IRF 3. Cell 122, 669-682 (2005).

68. Hornung, V. et al. 5'-Triphosphate RNA is the ligand for RIG-I. Science $\mathbf{3 1 4}$ 994-997 (2006)

69. Pichlmair, A. et al. RIG-I-mediated antiviral responses to single-stranded RNA bearing 5'-phosphates. Science 314, 997-1001 (2006).

70. Galluzzi, L., Kepp, O. \& Kroemer, G. Mitochondria: master regulators of danger signalling. Nat. Rev. Mol. Cell Biol. 13, 780-788 (2012).

71. Loo, Y. M. \& Gale, M. Jr. Immune signaling by RIG-l-like receptors. Immunity 34, 680-692 (2011)

72. Pourcelot, M. \& Arnoult, D. Mitochondrial dynamics and the innate antiviral immune response. FEBS J. 281, 3791-3802 (2014).

73. Kawai, T. \& Akira, S. Toll-like receptor and RIG--like receptor signaling. Ann. N. Y. Acad. Sci. 1143, 1-20 (2008).

74. Zeng, W. et al. Reconstitution of the RIG-I pathway reveals a signaling role of unanchored polyubiquitin chains in innate immunity. Cell 141, 315-330 (2010)

75. Yasukawa, K. et al. Mitofusin 2 inhibits mitochondrial antiviral signaling. Sci. Signal. 2, ra47 (2009).

76. Brinkmann, V. et al. Neutrophil extracellular traps kill bacteria. Science $\mathbf{3 0 3}$ 1532-1535 (2004).

77. Borregaard, N. Neutrophils, from marrow to microbes. Immunity 33, 657-670 (2010)

78. Ziegler, K. \& Unanue, E. R. Identification of a macrophage antigen-processing event required for I-region-restricted antigen presentation to $T$ lymphocytes. J. Immunol. 127, 1869-1875 (1981)

79. Sallusto, F. \& Lanzavecchia, A. Efficient presentation of soluble antigen by cultured human dendritic cells is maintained by granulocyte/macrophage colony-stimulating factor plus interleukin 4 and downregulated by tumor necrosis factor alpha. J. Exp. Med. 179, 1109-1118 (1994).

80. Bonifaz, L. et al. Efficient targeting of protein antigen to the dendritic cell receptor DEC-205 in the steady state leads to antigen presentation on major histocompatibility complex class I products and peripheral CD8+T cell tolerance. J. Exp. Med. 196, 1627-1638 (2002)

81. Mahnke, K., Schmitt, E., Bonifaz, L., Enk, A. H. \& Jonuleit, H. Immature, but not inactive: the tolerogenic function of immature dendritic cells. Immunol. Cell Biol. 80, 477-483 (2002)
82. Hartmann, G., Weiner, G. J. \& Krieg, A. M. CpG DNA: a potent signal for growth, activation, and maturation of human dendritic cells. Proc. Natl Acad. Sci. USA 96, 9305-9310 (1999).

83. Basu, S., Binder, R. J., Suto, R., Anderson, K. M. \& Srivastava, P. K. Necrotic but not apoptotic cell death releases heat shock proteins, which deliver a partial maturation signal to dendritic cells and activate the NF-kappa B pathway. Int. Immunol. 12, 1539-1546 (2000)

84. Cella, M. et al. Maturation, activation, and protection of dendritic cells induced by double-stranded RNA. J. Exp. Med. 189, 821-829 (1999).

85. Salio, M., Cella, M., Suter, M. \& Lanzavecchia, A. Inhibition of dendritic cell maturation by herpes simplex virus. Eur. J. Immunol. 29, 3245-3253 (1999).

86. Campello, S. et al. Orchestration of lymphocyte chemotaxis by mitochondrial dynamics. J. Exp. Med. 203, 2879-2886 (2006).

87. Campello, S. \& Scorrano, L. Mitochondrial shape changes: orchestrating cell pathophysiology. EMBO Rep. 11, 678-684 (2010).

88. Attardi, G. \& Schatz, G. Biogenesis of mitochondria. Annu. Rev. Cell Biol. 4 289-333 (1988)

89. McBride, H. M., Neuspiel, M. \& Wasiak, S. Mitochondria: more than just a powerhouse. Curr. Biol. 16, R551-R560 (2006)

90. Saraste, M. Oxidative phosphorylation at the fin de siecle. Science $\mathbf{2 8 3}$ 1488-1493 (1999).

91. Green, D. R. \& Kroemer, G. The pathophysiology of mitochondrial cell death. Science 305, 626-629 (2004).

92. Kroemer, G., Galluzzi, L. \& Brenner, C. Mitochondrial membrane permeabilization in cell death. Physiol. Rev. 87, 99-163 (2007).

93. Rizzuto, R., Bernardi, P. \& Pozzan, T. Mitochondria as all-round players of the calcium game. J. Physiol. 529, 37-47 (2000).

94. Cereghetti, G. M., Costa, V. \& Scorrano, L. Inhibition of Drp1-dependent mitochondrial fragmentation and apoptosis by a polypeptide antagonist of calcineurin. Cell Death Differ. 17, 1785-1794 (2010).

95. Cereghetti, G. M. et al. Dephosphorylation by calcineurin regulates translocation of Drp1 to mitochondria. Proc. Natl Acad. Sci. USA 105, 15803-15808 (2008).

96. Chan, D. C. Mitochondria: dynamic organelles in disease, aging, and development. Cell 125, 1241-1252 (2006).

97. Dimmer, K. S. \& Scorrano, L. (De)constructing mitochondria: what for? Physiology 21, 233-241 (2006).

98. Frezza, C. et al. OPA1 controls apoptotic cristae remodeling independently from mitochondrial fusion. Cell 126, 177-189 (2006).

99. Gomes, L. C., Di Benedetto, G. \& Scorrano, L. During autophagy mitochondria elongate, are spared from degradation and sustain cell viability. Nat. Cell Biol. 13, 589-598 (2011)

100. Scorrano, L. Proteins that fuse and fragment mitochondria in apoptosis: confissing a deadly con-fusion? J. Bioenerg. Biomembr. 37, 165-170 (2005).

101. Ingerman, E. et al. Dnm1 forms spirals that are structurally tailored to fit mitochondria. J. Cell Biol. 170, 1021-1027 (2005).

102. Mears, J. A. et al. Conformational changes in Dnm1 support a contractile mechanism for mitochondrial fission. Nat. Struct. Mol. Biol. 18, 20-26 (2011).

103. Otera, $\mathrm{H}$. et al. Mff is an essential factor for mitochondrial recruitment of Drp1 during mitochondrial fission in mammalian cells. J. Cell Biol. 191, 1141-1158 (2010)

104. Palmer, C. S. et al. MiD49 and MiD51, new components of the mitochondria fission machinery. EMBO Rep. 12, 565-573 (2011).

105. Yoon, Y., Krueger, E. W., Oswald, B. J. \& McNiven, M. A. The mitochondria protein hFis1 regulates mitochondrial fission in mammalian cells through an interaction with the dynamin-like protein DLP1. Mol. Cell Biol. 23, 5409-5420 (2003)

106. Yoon, Y., Pitts, K. R. \& McNiven, M. A. Mammalian dynamin-like protein DLP1 tubulates membranes. Mol. Biol. Cell 12, 2894-2905 (2001).

107. Zhao, J. et al. Human MIEF1 recruits Drp1 to mitochondrial outer membranes and promotes mitochondrial fusion rather than fission. EMBO J. $\mathbf{3 0}$ 2762-2778 (2011).

108. Brooks, C. et al. Bak regulates mitochondrial morphology and pathology during apoptosis by interacting with mitofusins. Proc. Natl Acad. Sci. USA 104, 11649-11654 (2007).

109. Karbowski, M. et al. Quantitation of mitochondrial dynamics by photolabeling of individual organelles shows that mitochondrial fusion is blocked during the Bax activation phase of apoptosis. J. Cell Biol. 164, 493-499 (2004).

110. Karbowski, M. et al. Spatial and temporal association of Bax with mitochondrial fission sites, Drp1, and Mfn2 during apoptosis. J. Cell Biol. 159, 931-938 (2002) 
111. Wasiak, S., Zunino, R. \& McBride, H. M. Bax/Bak promote sumoylation of DRP1 and its stable association with mitochondria during apoptotic cell death. $J$. Cell Biol. 177, 439-450 (2007).

112. Griparic, L., Kanazawa, T. \& van der Bliek, A. M. Regulation of the mitochondrial dynamin-like protein Opa1 by proteolytic cleavage. J. Cell Biol. 178 757-764 (2007)

113. Ishihara, N., Fujita, Y., Oka, T. \& Mihara, K. Regulation of mitochondrial morphology through proteolytic cleavage of OPA1. EMBO J. 25, 2966-2977 (2006).

114. Cipolat, S., Martins de Brito, O., Dal Zilio, B. \& Scorrano, L. OPA1 requires mitofusin 1 to promote mitochondrial fusion. Proc. Natl Acad. Sci. USA 101 15927-15932 (2004).

115. Cipolat, S. et al. Mitochondrial rhomboid PARL regulates cytochrome c release during apoptosis via OPA1-dependent cristae remodeling. Cell 126, 163-175 (2006).

116. Cogliati, S. et al. Mitochondrial cristae shape determines respiratory chain supercomplexes assembly and respiratory efficiency. Cell 155, 160-171 (2013).

117. Liu, X. \& Hajnoczky, G. Ca2+-dependent regulation of mitochondrial dynamics by the Miro-Milton complex. Int. J. Biochem. Cell Biol. 41, 1972-1976 (2009)

118. da Silva, A. F., Mariotti, F. R., Maximo, V. \& Campello, S. Mitochondria dynamism: of shape, transport and cell migration. Cell Mol. life Sci. 71, 2313-2324 (2014).

119. Hollenbeck, P. J. \& Saxton, W. M. The axonal transport of mitochondria. J. Cell Sci. 118, 5411-5419 (2005).

120. Korobova, F., Gauvin, T. J. \& Higgs, H. N. A role for myosin II in mammalian mitochondrial fission. Curr. Biol. 24, 409-414 (2014).

121. MacAskill, A. F., Brickley, K., Stephenson, F. A. \& Kittler, J. T. GTPase dependent recruitment of Grif-1 by Miro1 regulates mitochondrial trafficking in hippocampal neurons. Mol. Cell Neurosci. 40, 301-312 (2009).

122. Tanaka, Y. et al. Targeted disruption of mouse conventional kinesin heavy chain, kif5B, results in abnormal perinuclear clustering of mitochondria. Cell 93, 1147-1158 (1998).

123. Saotome, M. et al. Bidirectional Ca2 + -dependent control of mitochondrial dynamics by the Miro GTPase. Proc. Natl Acad. Sci. USA 105, 20728-20733 (2008).

124. Macaskill, A. F. et al. Miro1 is a calcium sensor for glutamate receptordependent localization of mitochondria at synapses. Neuron 61, 541-555 (2009).

125. Kornmann, B., Osman, C. \& Walter, P. The conserved GTPase Gem1 regulates endoplasmic reticulum-mitochondria connections. Proc. Natl Acad. Sci. USA 108, 14151-14156 (2011)

126. Glater, E. E., Megeath, L. J., Stowers, R. S. \& Schwarz, T. L. Axonal transport of mitochondria requires milton to recruit kinesin heavy chain and is light chain independent. J. Cell Biol. 173, 545-557 (2006)

127. Stowers, R. S., Megeath, L. J., Gorska-Andrzejak, J., Meinertzhagen, I. A. \& Schwarz, T. L. Axonal transport of mitochondria to synapses depends on milton, a novel Drosophila protein. Neuron 36, 1063-1077 (2002).

128. Nunes, P. \& Demaurex, N. Redox regulation of store-operated Ca2+ entry. Antioxid. Redox Signal. 21, 915-932 (2014).

129. Ben-Kasus Nissim, T. et al. Mitochondria control store-operated Ca2+ entry through $\mathrm{Na}+$ and redox signals. EMBO J. 36, 797-815 (2017).

130. Bogeski, I. et al. Differential redox regulation of ORAl ion channels: a mechanism to tune cellular calcium signaling. Sci. Signal. 3, ra24 (2010).

131. De Stefani, D., Raffaello, A., Teardo, E., Szabo, I. \& Rizzuto, R. A forty-kilodalton protein of the inner membrane is the mitochondrial calcium uniporter. Nature 476, 336-340 (2011)

132. Baughman, J. M. et al. Integrative genomics identifies MCU as an essential component of the mitochondrial calcium uniporter. Nature 476, 341-345 (2011)

133. Prakriya, M. et al. Orai1 is an essential pore subunit of the CRAC channel. Nature 443, 230-233 (2006).

134. Vig, M. et al. CRACM1 is a plasma membrane protein essential for storeoperated Ca2+ entry. Science 312, 1220-1223 (2006).

135. Mikoshiba, K. IP3 receptor/Ca2+ channel: from discovery to new signaling concepts. J. Neurochem. 102, 1426-1446 (2007).

136. Putney, J. W. Jr. A model for receptor-regulated calcium entry. Cell Calcium 7 $1-12$ (1986).

137. Szabadkai, G. et al. Chaperone-mediated coupling of endoplasmic reticulum and mitochondrial Ca2+ channels. J. Cell Biol. 175, $901-911$ (2006).
138. Marchi, S. et al. Selective modulation of subtype III IP(3)R by Akt regulates ER $\mathrm{Ca}(2)(+)$ release and apoptosis. Cell Death Dis. 3, e304 (2012).

139. Marchi, S. et al. Akt kinase reducing endoplasmic reticulum Ca2+release protects cells from Ca2+-dependent apoptotic stimuli. Biochem. Biophys. Res. Commun. 375, 501-505 (2008).

140. Giorgi, C. et al. PML regulates apoptosis at endoplasmic reticulum by modulating calcium release. Science 330, 1247-1251 (2010).

141. De Vos, K. J. et al. VAPB interacts with the mitochondrial protein PTPIP51 to regulate calcium homeostasis. Hum. Mol. Genet. 21, 1299-1311 (2012)

142. Denton, R. M., McCormack, J. G. \& Edgell, N. J. Role of calcium ions in the regulation of intramitochondrial metabolism. Effects of $\mathrm{Na}+\mathrm{Mg} 2+$ and ruthenium red on the $\mathrm{Ca} 2+$-stimulated oxidation of oxoglutarate and on pyruvate dehydrogenase activity in intact rat heart mitochondria. Biochem. J. 190, 107-117 (1980)

143. McCormack, J. G. \& Denton, R. M. Role of calcium ions in the regulation of intramitochondrial metabolism. Properties of the Ca2+ -sensitive dehydrogenases within intact uncoupled mitochondria from the white and brown adipose tissue of the rat. Biochem. J. 190, 95-105 (1980).

144. Denton, R. M., Richards, D. A. \& Chin, J. G. Calcium ions and the regulation of NAD+ -linked isocitrate dehydrogenase from the mitochondria of rat heart and other tissues. Biochem. J. 176, 899-906 (1978).

145. Scorrano, L. et al. BAX and BAK regulation of endoplasmic reticulum Ca2+: a control point for apoptosis. Science 300, 135-139 (2003)

146. Hajnoczky, G. et al. Mitochondrial calcium signalling and cell death: approaches for assessing the role of mitochondrial Ca2+ uptake in apoptosis. Cell Calcium 40, 553-560 (2006)

147. Ziegler, H. K. \& Unanue, E. R. Decrease in macrophage antigen catabolism caused by ammonia and chloroquine is associated with inhibition of antigen presentation to T cells. Proc. Natl Acad. Sci. USA 79, 175-178 (1982)

148. Mantegazza, A. R., Magalhaes, J. G., Amigorena, S. \& Marks, M. S. Presentation of phagocytosed antigens by MHC class I and II. Traffic 14, 135-152 (2013).

149. Blum, J. S., Wearsch, P. A. \& Cresswell, P. Pathways of antigen processing. Annu. Rev. Immunol. 31, 443-473 (2013).

150. Hildner, K. et al. Batf3 deficiency reveals a critical role for CD8alpha+ dendritic cells in cytotoxic T cell immunity. Science 322, 1097-1100 (2008).

151. Savina, A. et al. The small GTPase Rac2 controls phagosomal alkalinization and antigen crosspresentation selectively in CD8(+) dendritic cells. Immunity 30, 544-555 (2009)

152. Russmann, $\mathrm{H}$. et al. Alternative endogenous protein processing via an autophagy-dependent pathway compensates for Yersinia-mediated inhibition of endosomal major histocompatibility complex class $\|$ antigen presentation. Infect. Immun. 78, 5138-5150 (2010).

153. Thurston, T. L., Ryzhakov, G., Bloor, S., von Muhlinen, N. \& Randow, F. The TBK1 adaptor and autophagy receptor NDP52 restricts the proliferation of ubiquitin-coated bacteria. Nat. Immunol. 10, 1215-1221 (2009).

154. Yano, T. et al. Autophagic control of listeria through intracellular innate immune recognition in drosophila. Nat. Immunol. 9, 908-916 (2008).

155. Crotzer, V. L. \& Blum, J. S. Autophagy and its role in MHC-mediated antigen presentation. J. Immunol. 182, 3335-3341 (2009).

156. Dengjel, J. et al. Autophagy promotes MHC class II presentation of peptides from intracellular source proteins. Proc. Natl Acad. Sci. USA 102, 7922-7927 (2005)

157. Ma, Y., Galluzzi, L., Zitvogel, L. \& Kroemer, G. Autophagy and cellular immune responses. Immunity 39, 211-227 (2013).

158. English, L. et al. Autophagy enhances the presentation of endogenous vira antigens on MHC class I molecules during HSV-1 infection. Nat. Immunol. 10 480-487 (2009).

159. Li, Y. et al. Efficient cross-presentation depends on autophagy in tumor cells. Cancer Res. 68, 6889-6895 (2008).

160. Uhl, M. et al. Autophagy within the antigen donor cell facilitates efficient antigen cross-priming of virus-specific CD8+T cells. Cell Death Differ. 16, 991-1005 (2009)

161. Jia, W., Pua, H. H., Li, Q. J. \& He, Y. W. Autophagy regulates endoplasmic reticulum homeostasis and calcium mobilization in $\mathrm{T}$ lymphocytes. J. Immunol. 186, 1564-1574 (2011)

162. Pua, H. H., Dzhagalov, I., Chuck, M., Mizushima, N. \& He, Y. W. A critical role for the autophagy gene Atg5 in T cell survival and proliferation. J. Exp. Med. 204, 25-31 (2007)

163. Levine, B., Mizushima, N. \& Virgin, H. W. Autophagy in immunity and inflammation. Nature 469, 323-335 (2011). 
164. Yang, Z. \& Klionsky, D. J. Eaten alive: a history of macroautophagy. Nat. Cell Biol. 12, 814-822 (2010).

165. Komatsu, M. et al. Impairment of starvation-induced and constitutive autophagy in Atg7-deficient mice. J. Cell Biol. 169, 425-434 (2005).

166. Li, L., Chen, Y. \& Gibson, S. B. Starvation-induced autophagy is regulated by mitochondrial reactive oxygen species leading to AMPK activation. Cell Signal. 25, 50-65 (2013).

167. Mizushima, N. The role of the Atg1/ULK1 complex in autophagy regulation. Curr. Opin. Cell Biol. 22, 132-139 (2010).

168. Itakura, E. \& Mizushima, N. Characterization of autophagosome formation site by a hierarchical analysis of mammalian Atg proteins. Autophagy 6, 764-776 (2010).

169. Matsunaga, K. et al. Two Beclin 1-binding proteins, Atg14L and Rubicon, reciprocally regulate autophagy at different stages. Nat. Cell Biol. 11, 385-396 (2009)

170. Axe, E. L. et al. Autophagosome formation from membrane compartments enriched in phosphatidylinositol 3-phosphate and dynamically connected to the endoplasmic reticulum. J. Cell Biol. 182, 685-701 (2008).

171. Ktistakis, N. T., Andrews, S. \& Long, J. What is the advantage of a transient precursor in autophagosome biogenesis? Autophagy 7, 118-122 (2011).

172. Fujita, N. et al. An Atg4B mutant hampers the lipidation of LC3 paralogues and causes defects in autophagosome closure. Mol. Biol. Cell 19, 4651-4659 (2008)

173. Fujita, N. et al. The Atg16L complex specifies the site of LC3 lipidation for membrane biogenesis in autophagy. Mol. Biol. Cell 19, 2092-2100 (2008).

174. Itoh, T. et al. Golgi-resident small GTPase Rab33B interacts with Atg16L and modulates autophagosome formation. Mol. Biol. Cell 19, 2916-2925 (2008).

175. Weidberg, H., Shpilka, T., Shvets, E. \& Elazar, Z. Mammalian Atg8s: one is simply not enough. Autophagy 6, 808-809 (2010).

176. Weidberg, H. et al. LC3 and GATE-16/GABARAP subfamilies are both essential yet act differently in autophagosome biogenesis. EMBO J. 29, 1792-1802 (2010).

177. Hamasaki, M., Shibutani, S. T. \& Yoshimori, T. Up-to-date membrane biogenesis in the autophagosome formation. Curr. Opin. Cell Biol. 25, 455-460 (2013).

178. Kim, U. et al. The B-cell-specific transcription coactivator OCA-B/OBF-1/Bob-1 is essential for normal production of immunoglobulin isotypes. Nature $\mathbf{3 8 3}$ 542-547 (1996).

179. Huppa, J. B., Gleimer, M., Sumen, C. \& Davis, M. M. Continuous T cell receptor signaling required for synapse maintenance and full effector potential. Nat. Immunol. 4, 749-755 (2003).

180. Chen, L. et al. Expression of ZAP-70 is associated with increased B-cell receptor signaling in chronic lymphocytic leukemia. Blood 100, 4609-4614 (2002)

181. Schubart, D. B., Rolink, A., Kosco-Vilbois, M. H., Botteri, F. \& Matthias, P. B-cellspecific coactivator OBF-1/OCA-B/Bob1 required for immune response and germinal centre formation. Nature 383, 538-542 (1996).

182. Brass, A. L., Zhu, A. Q. \& Singh, H. Assembly requirements of PU.1-Pip (IRF-4) activator complexes: inhibiting function in vivo using fused dimers. EMBO $\mathrm{J}$. 18, 977-991 (1999)

183. Nishizuka, Y. Protein kinase $C$ and lipid signaling for sustained cellular responses. FASEB J. 9, 484-496 (1995).

184. Tedder, T. F. \& Engel, P. CD20: a regulator of cell-cycle progression of B lymphocytes. Immunol. Today 15, 450-454 (1994).

185. Tedder, T. F., Zhou, L. J. \& Engel, P. The CD19/CD21 signal transduction complex of B lymphocytes. Immunol. Today 15, 437-442 (1994).

186. Trushin, S. A. et al. Protein kinase Calpha (PKCalpha) acts upstream of PKCtheta to activate IkappaB kinase and NF-kappaB in T lymphocytes. Mol. Cell Biol. 23, 7068-7081 (2003).

187. Ho, P. C. et al. Phosphoenolpyruvate is a metabolic checkpoint of anti-tumor T cell responses. Cell 162, 1217-1228 (2015).

188. Chang, C. H. et al. Metabolic competition in the tumor microenvironment is a driver of cancer progression. Cell 162, 1229-1241 (2015).

189. Parekh, A. B. \& Putney, J. W. J. Store-operated calcium channels. Physiol. Rev. 85, 757-810 (2005)

190. Bathori, G., Csordas, G., Garcia-Perez, C., Davies, E. \& Hainoczky, G. Ca2+ -dependent control of the permeability properties of the mitochondrial outer membrane and voltage-dependent anion-selective channel (VDAC). J. Biol. Chem. 281, 17347-17358 (2006).
191. Lee, A. C., Xu, X., Blachly-Dyson, E., Forte, M. \& Colombini, M. The role of yeast VDAC genes on the permeability of the mitochondrial outer membrane. J. Membr. Biol. 161, 173-181 (1998).

192. Norberg, E. et al. An increase in intracellular $\mathrm{Ca} 2+$ is required for the activation of mitochondrial calpain to release AIF during cell death. Cell Death Differ. 15, 1857-1864 (2008).

193. Petrosillo, G., Ruggiero, F. M., Pistolese, M. \& Paradies, G. Ca2+ -induced reactive oxygen species production promotes cytochrome $\mathrm{c}$ release from rat liver mitochondria via mitochondrial permeability transition (MPT)-dependent and MPT-independent mechanisms: role of cardiolipin. J. Biol. Chem. 279, 53103-53108 (2004)

194. Alirol, E. et al. The mitochondrial fission protein hFis1 requires the endoplasmic reticulum gateway to induce apoptosis. Mol. Biol. Cell 17, 4593-4605 (2006)

195. Lee, Y. J., Jeong, S. Y., Karbowski, M., Smith, C. L. \& Youle, R. J. Roles of the mammalian mitochondrial fission and fusion mediators Fis1, Drp1, and Opa1 in apoptosis. Mol. Biol. Cell 15, 5001-5011 (2004).

196. Yu, T., Fox, R. J., Burwell, L. S. \& Yoon, Y. Regulation of mitochondrial fission and apoptosis by the mitochondrial outer membrane protein hFis1. J. Cell Sci. 118, 4141-4151 (2005).

197. Krammer, P. H., Arnold, R. \& Lavrik, I. N. Life and death in peripheral T cells. Nat. Rev. Immunol. 7, 532-542 (2007).

198. Takahama, Y. Journey through the thymus: stromal guides for T-cell development and selection. Nat. Rev. Immunol. 6, 127-135 (2006).

199. Carsetti, R., Kohler, G. \& Lamers, M. C. Transitional B cells are the target of negative selection in the B cell compartment. J. Exp. Med. 181, 2129-2140 (1995).

200. Smith, K. A. Edward jenner and the small pox vaccine. Front. Immunol. 2, 21 (2011)

201. Smith, K. A. Louis pasteur, the father of immunology? Front. Immunol. 3, 68 (2012)

202. Corthay, A. Does the immune system naturally protect against cancer? Front. Immunol. 5, 197 (2014)

203. Salavoura, K, Kolialexi, A., Tsangaris, G. \& Mavrou, A. Development of cancer in patients with primary immunodeficiencies. Anticancer Res. 28(2B), 1263-1269 (2008)

204. Kawai, O. et al. Predominant infiltration of macrophages and CD8(+) T Cells in cancer nests is a significant predictor of survival in stage IV nonsmall cell lung cancer. Cancer 113, 1387-1395 (2008).

205. Galon, J, et al. Type, density, and location of immune cells within human colorectal tumors predict clinical outcome. Science 313, 1960-1964 (2006).

206. Guiguet, M. et al. Effect of immunodeficiency, HIV viral load, and antiretroviral therapy on the risk of individual malignancies (FHDH-ANRS CO4): a prospective cohort study. Lancet Oncol. 10, 1152-1159 (2009).

207. Brahmer, J. R. \& Pardoll, D. M. Immune checkpoint inhibitors: making immunotherapy a reality for the treatment of lung cancer. Cancer Immunol. Res. 1, 85-91 (2013).

208. Topalian, S. L. et al. Safety, activity, and immune correlates of anti-PD-1 antibody in cancer. N. Engl. J. Med. 366, 2443-2454 (2012).

209. van der Weyden, L. et al. Genome-wide in vivo screen identifies novel host regulators of metastatic colonization. Nature 541, 233-236 (2017).

210. Senovilla, L. et al. An immunosurveillance mechanism controls cancer cell ploidy. Science 337, 1678-1684 (2012).

211. Shankaran, V. et al. IFNgamma and lymphocytes prevent primary tumour development and shape tumour immunogenicity. Nature 410, 1107-1111 (2001).

212. Facoetti, A. et al. Human leukocyte antigen and antigen processing machinery component defects in astrocytic tumors. Clin. Cancer Res. 11 8304-8311 (2005)

213. Govindan, R. et al. Genomic landscape of non-small cell lung cancer in smokers and never-smokers. Cell 150, 1121-1134 (2012).

214. Hanahan, D. \& Weinberg, R. A. Hallmarks of cancer: the next generation. Cell 144, 646-674 (2011).

215. Hoa, N. et al. Glioma cells display complex cell surface topographies that resist the actions of cytolytic effector lymphocytes. J. Immunol. 185, 4793-4803 (2010)

216. Paszek, M. J. et al. The cancer glycocalyx mechanically primes integrinmediated growth and survival. Nature 511, 319-325 (2014).

217. Barcia, C. et al. Infiltrating CTLs in human glioblastoma establish immunological synapses with tumorigenic cells. Am. J. Pathol. 175, 786-798 (2009). 
218. Comrie, W. A., Babich, A. \& Burkhardt, J. K. F-actin flow drives affinity maturation and spatial organization of LFA-1 at the immunological synapse. J. Cell Biol. 208, 475-491 (2015).

219. Chiusolo, V. et al. Granzyme B enters the mitochondria in a Sam50-, Tim22 and $\mathrm{mtH}$ sp70-dependent manner to induce apoptosis. Cell Death Differ. 24 747-758 (2017)

220. Jacquemin, G. et al. Granzyme B-induced mitochondrial ROS are required for apoptosis. Cell Death Differ. 22, 862-874 (2015)

221. Martinvalet, D., Dykxhoorn, D. M., Ferrini, R. \& Lieberman, J. Granzyme A cleaves a mitochondrial complex I protein to initiate caspase-independent cell death. Cell 133, 681-692 (2008).

222. Martinvalet, D., Zhu, P. \& Lieberman, J. Granzyme A induces caspaseindependent mitochondrial damage, a required first step for apoptosis. Immunity 22, 355-370 (2005).

223. Thiery, J. et al. Perforin pores in the endosomal membrane trigger the release of endocytosed granzyme B into the cytosol of target cells. Nat. Immunol. 12 770-777 (2011).

224. Martinvalet, D. \& Thiery, J. A novel caspase-independent apoptotic pathway triggered by Granzyme A. Med. Sci. 24, 901-903 (2008).

225. Castro, M. G. et al. Current and future strategies for the treatment of malignant brain tumors. Pharmacol. Ther. 98, 71-108 (2003).

226. Bassoy, E. Y. et al. ER-mitochondria contacts control surface glycan expression and sensitivity to killer lymphocytes in glioma stem-like cells. EMBO J. $\mathbf{3 6}$ 1493-1512 (2017).

227. Chen, J. et al. A restricted cell population propagates glioblastoma growth after chemotherapy. Nature 488, 522-526 (2012).

228. Suva, M. L. et al. Reconstructing and reprogramming the tumor-propagating potential of glioblastoma stem-like cells. Cell 157, 580-594 (2014).

229. Singh, S. K. et al. Identification of human brain tumour initiating cells. Nature 432, 396-401 (2004).

230. Patel, A. P. et al. Single-cell RNA-seq highlights intratumoral heterogeneity in primary glioblastoma. Science 344, 1396-1401 (2014).

231. Bassoy, E. Y. et al. Glioma stemlike cells enhance the killing of glioma differentiated cells by cytotoxic lymphocytes. PLOS ONE 11, e0153433 (2016).

232. Xie, Q. et al. Mitochondrial control by DRP1 in brain tumor initiating cells. Nat. Neurosci. 18, 501-510 (2015)

233. de Brito, O. M. \& Scorrano, L. Mitofusin 2 tethers endoplasmic reticulum to mitochondria. Nature 456, 605-610 (2008).

234. Naon, D. et al. Critical reappraisal confirms that Mitofusin 2 is an endoplasmic reticulum-mitochondria tether. Proc. Natl Acad. Sci. USA 113, 11249-11254 (2016)

235. Kleene, R. \& Schachner, M. Glycans and neural cell interactions. Nat. Rev. Neurosci. 5, 195-208 (2004).

236. Ohtsubo, K. \& Marth, J. D. Glycosylation in cellular mechanisms of health and disease. Cell 126, 855-867 (2006).

237. Tuccillo, F. M. et al. Aberrant glycosylation as biomarker for cancer: focus on CD43. Biomed. Res. Int. 2014, 742831 (2014).

238. Kannagi, R., Izawa, M., Koike, T., Miyazaki, K. \& Kimura, N. Carbohydratemediated cell adhesion in cancer metastasis and angiogenesis. Cancer Sci. 95, 377-384 (2004)
239. Dimitroff, C. J. et al. Cell surface n-acetylneuraminic acidalpha2,3-galactosidedependent intercellular adhesion of human colon cancer cells. Biochem. Biophys. Res. Commun. 256, 631-636 (1999).

240. Fuster, M. M., Brown, J. R., Wang, L. \& Esko, J. D. A disaccharide precursor of sialyl Lewis $X$ inhibits metastatic potential of tumor cells. Cancer Res. $\mathbf{6 3}$, 2775-2781 (2003)

241. Ardail, D. et al. The mitochondria-associated endoplasmic-reticulum subcompartment (MAM fraction) of rat liver contains highly active sphingolipidspecific glycosyltransferases. Biochem. J. 371, 1013-1019 (2003).

242. Bionda, C., Portoukalian, J., Schmitt, D., Rodriguez-Lafrasse, C. \& Ardail, D. Subcellular compartmentalization of ceramide metabolism: MAM (mitochondria-associated membrane) and/or mitochondria? Biochem. J. 382, 527-533 (2004)

243. Mullen, T. D., Hannun, Y. A. \& Obeid, L. M. Ceramide synthases at the centre of sphingolipid metabolism and biology. Biochem. J. 441, 789-802 (2012)

244. Kornmann, B. \& Walter, P. ERMES-mediated ER-mitochondria contacts: molecular hubs for the regulation of mitochondrial biology. J. Cell Sci. 123 1389-1393 (2010)

245. De Mario, A., Quintana-Cabrera, R., Martinvalet, D. \& Giacomello, M. (Neuro) degenerated Mitochondria-ER contacts. Biochem. Biophys. Res. Commun. $\mathbf{4 8 3}$ 1096-1109 (2016)

246. Hirabayashi, Y. et al. ER-mitochondria tethering by PDZD8 regulates Ca2+ dynamics in mammalian neurons. Science 358, 623-630 (2017)

247. Vance, J. E. Phospholipid synthesis in a membrane fraction associated with mitochondria. J. Biol. Chem. 265, 7248-7256 (1990).

248. Salomoni, P. \& Pandolfi, P. P. The role of PML in tumor suppression. Cell $\mathbf{1 0 8}$ 165-170 (2002)

249. Betz, C. et al. Feature article: mTOR complex 2-Akt signaling at mitochondriaassociated endoplasmic reticulum membranes (MAM) regulates mitochondrial physiology. Proc. Natl Acad. Sci. USA 110, 12526-12534 (2013).

250. Raturi, A. \& Simmen, T. Where the endoplasmic reticulum and the mitochondrion tie the knot: the mitochondria-associated membrane (MAM). Biochim. Et. Biophys. Acta 1833, 213-224 (2013).

251. Simmen, T. et al. PACS-2 controls endoplasmic reticulum-mitochondria communication and Bid-mediated apoptosis. EMBO J. 24, 717-729 (2005)

252. Masui, S., Vavassori, S., Fagioli, C., Sitia, R. \& Inaba, K. Molecular bases of cyclic and specific disulfide interchange between human ERO1alpha protein and protein-disulfide isomerase (PDI). J. Biol. Chem. 286, 16261-16271 (2011).

253. May, D. et al. Ero1-L alpha plays a key role in a HIF-1-mediated pathway to improve disulfide bond formation and VEGF secretion under hypoxia: implication for cancer. Oncogene 24, 1011-1020 (2005).

254. Higo, T. et al. Subtype-specific and ER lumenal environment-dependent regulation of inositol 1,4,5-trisphosphate receptor type 1 by ERp44. Cell 120 85-98 (2005).

255. Kroemer, G., Galluzzi, L., Kepp, O. \& Zitvogel, L. Immunogenic cell death in cancer therapy. Annu. Rev. Immunol. 31, 51-72 (2013).

256. De Mario, A., Quintana-Cabrera, R., Martinvalet, D. \& Giacomello, M. Neuro) degenerated Mitochondria-ER contacts. Biochem. Biophys. Res. Commun. 483, 1096-1109 (2017).

257. Vance, J. E. M. A. M. (mitochondria-associated membranes) in mammalian cells: lipids and beyond. Biochim. Biophys. Acta 1841, 595-609 (2014). 